\title{
Down to the wire in the Pacific
}

\section{Tokyo}

JAPANESE and US seismologists have found a novel use for a discarded transoceanic telephone cable: they plan to make it into a seismic sensor.

Last week, the telecommunication companies American Telephone and Telegraph Co. (AT\&T) and Japan's Kokusai Denshin Denwa (KDD) donated the Guam-to-Japan section of an old trans-Pacific telephone cable, TPC-1, to US and Japanese seismologists, who will use it to connect a network of highly sensitive submarine seismometers and geophysical instruments on the deep-sea floor of the western Pacific. This local setup will eventually become part of a much larger global seismic network.

The Geophysical and Oceanographical Trans-Ocean Cable (GEO-TOC) project, first proposed in 1987, was intended to be part of the bigger POSEIDON (for Pacific Orient Seismic Digital Observation Net-

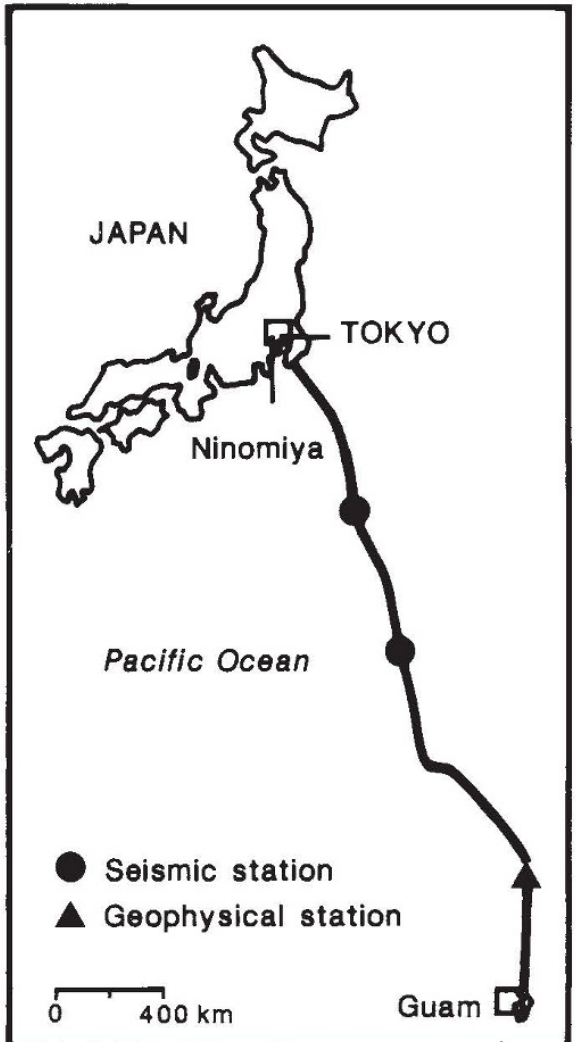

work) project, an ambitious proposal by Japanese seismologists to establish a network of 50 supersensitive seismometers on the ocean floor and on land in the western Pacific region. But POSEIDON has so far not been granted money by the miserly Ministry of Education, Science and Culture (MESC), and researchers at the Earthquake Research Institute of Tokyo University decided to go it alone with GEOTOC.

The TPC-1 cable became largely redundant in 1988 after the completion of a new optical fibre cable (TPC. 3 ) between the United States and Japan. But the sections of TPC- 1 between Guam and Hawaii and the mainland of the United States are still in use, so only the Japan to Guam section is now available for scientific purposes. If GEO-TOC proves its worth, US and Japanese scientists hope to take over the rest of the TPC-1 cable as well as other trans-Pacific telephone cables.

The GEO-TOC network will consist of three permanent submarine stations with seismometers capable of detecting a very broad range of frequencies of vibration. One station (near Guam) will also have geoelectric and geomagnetic sensors, magnetometers, a tsunami sensor (to detect tidal waves), deep-sea current meters and other physical oceanographic equipment. Data will be relayed to both ends of the TPC- 1 cable.

GEO-TOC will yield continuous realtime data from the back-arc region of the Izu-Ogasawara and Mariana subduction zones where the Pacific tectonic plate plunges beneath the Philippine plate.

The data should help to elucidate the internal structure of the Earth near the plate boundary and will also be useful for earthquake prediction. GEO-TOC, in concert with the US IRIS project and the French GEOSCOPE project, will form part of a huge global network of seismometers that will continuously monitor seismic activity around the Earth.

Japan will provide the ocean-floor instrumentation and data-processing facilities in Japan, and US seismologists hope to get funds from the National Science Foundation to establish a data-processing centre on Guam. MESC initially balked at supporting a project that involves giving foreigners free and unlimited access to 'national property', something MESC has never done before. But the Earthquake Research Institute eventually won a threeyear grant of a few hundred thousand dollars this fiscal year to try out a 3-km test cable off the coast of Japan. And MESC has applied for funds in next fiscal year to begin the main project.

Junzo Kasahara of the institute estimates that the project will require about $¥ 2,000$ million ( $\$ 15$ million) over seven years - a lot of money for MESC but much less than would have been needed if scientists had laid their own cable. TPC-1 is over 26 years old and some experts fear that it may not have much life left in it. But Kasahara and other GEO-TOC supporters are confident the cable can be kept in operation for at least another ten years.

David Swinbanks

- A new method of searching for electromagnetic precursors of earthquakes is presented on page 376 of this issue.
New highest- $T_{\mathrm{c}}$ claim

HiтACHi last week claimed to have developed a new type of vanadium-based oxide superconductor with a critical temperature of $130 \mathrm{~K}$. That is 5 degrees above the critical temperature of the thallium-based superconductors which have held the record for high- $T_{\text {c }}$ superconductivity for over two years. The claim is of special interest because the new material, a thalliumstrontium-vanadium oxide, contains no copper. So far, the only other copper-free high-temperature superconductor, bariumpotassium-bismuth oxide, has a much lower critical temperature of $30 \mathrm{~K}$.

But there is some scepticism about the Hitachi claim. The company says the new material has two superconducting phases with critical temperatures of $130 \mathrm{~K}$ and 30 $K$. But the Meisner effect, a key indicator of superconductivity, has been observed only in the $30-\mathrm{K}$ phase. The electrical properties of the material are described as "not stable in the ambient atmosphere" in a paper submitted to the Japanese Journal of Applied Physics. In the past, many reports of 'unstable' superconductivity have been false alarms.

D.S.

\section{Porcine problem now}

RESEARCHERS from the UK Agricultural Ministry's Central Veterinary Laboratory in Hertfordshire have transmitted bovine spongiform encephalopathy to 1 of 10 pigs injected with large doses of infected cattle brain. A second experiment to test if pigs can contract the disease by eating infected material is still in progress. The Tyrrell Scientific Committee, which advises the government on the spongiform encephalopathies, believes the announcement does not increase the risk to human health, but has recommended that the cattle offals currently banned for human consumption should be excluded from all animal feed. The ban came into force on midnight of Monday of this week, only a few hours after the announcement.

P.A.

\section{A woman's place}

IN the three months since the US General Accounting Office criticized the National Institutes of Health (NIH) for favouring men in clinical trials, much has changed. First NIH reissued a policy statement, emphasizing that all deviations from a balanced gender representation in research studies must be explained. Then the Senate's reauthorization for NIH required NIH researchers to insure that their studies are statistically representative of the population at large, by both sex and race. Earlier this month Bernadine Healy was picked to be NIH's new director. And the latest development is the creation of an Office on Research on Women's Health, to be headed by Ruth Kirschstein, director of the National Institute of General Medical Sciences. 